\title{
A method for assessing the stress-strain state of reinforced concrete structures
}

\author{
Andrew Varlamov ${ }^{1}$, Vladimir Rimshin ${ }^{2}$, and Sergey Tverskoi ${ }^{3, *}$ \\ ${ }^{1}$ Nosov Magnitogorsk State Technical University (NMSTU), pr. Lenina, 38, Magnitogorsk, 455000, \\ Russia \\ ${ }^{2}$ NIISF RAASN, 127238, Moscow, Russia \\ ${ }^{3} J S C$ "MGrP", 455028, Magnitogorsk, Russia
}

\begin{abstract}
The article analyses the modern methods of estimation of stress-strain state of reinforced concrete structures. The result of the analysis is a new method for estimating the stress-strain state of reinforced concrete structures. The method is based on extracting a small sample of concrete from the array. The article describes the method of execution of works, the method of calculating the stresses. Previously, the method was investigated under laboratory conditions. The results are presented in graphs and tables. The research was conducted to assess the stress state of existing concrete structures. As the objects of research, two industrial buildings of 1933 and 1941 construction years were taken. An assessment of a stress state of a panel residential building was held. The measurement results were analyzed. The method for determining the stresses in reinforced concrete buildings and structures is recommended.
\end{abstract}

\section{Introduction}

At all stages of design, construction and operation, a proper assessment of technical condition of the building structures is necessary. It makes it possible to increase the reliability and durability of structures. When inspecting buildings and structures, it is often necessary to evaluate the stress-strain state (SSS) of structures. In this case, it is possible to compare the characteristics of the material with the actual stresses. Currently, the actual stresses in structures in most cases are determined analytically. Experimental determination of SSS of full-scale structures is used in very critical cases due to its high labor intensity and costs. Therefore, the development of an effective experimental method for SSS assessing is an actual challenge. Review of stress measurement methods in concrete.

Experimental methods for measuring stresses and strains can be divided into the following ones:

a) calculation of stress on the measured deformations [1-4];

b) associated with changes in the physical properties of materials under the action of mechanical stresses;

c) compensatory.

\footnotetext{
* Corresponding author: mgrp77@mail.ru
} 
Measurement of deformations is carried out on the structure surface and inside the structure material.

\section{Method of local load relief}

The essence of the method lies in the fact that after removal of the initial deformations, the structure is partially unloaded, after that the second readings on the instruments are taken. According to the difference in readings, the difference in deformations and the corresponding stresses, which acted in the given section of the structure before the removal of the load, are calculated. So in the works of Pavlov P.A [5], Yakubovsky B.V., Ermolaev N.N., Akridin D.V. [2] the unloading was carried out by cutting a ring groove with a depth of $3 / 4$ of the diameter of a circle around the outlet of strain gauges. A similar method is used in the evaluation of stresses in massive rocks [6]. Essentially, a mechanical method in the form of a ring-groove method is encountered with only one limitation - a safety consideration for a device for durability of structures, which in most cases cannot be an obstacle for measurements in stone and concrete structures. A transition from deformations to stresses is performed most simply in the presence of a linear law of unloading. But stresses can also be calculated in case of deviations from the linear law, if the material deformation curves are studied sufficiently. A similar method (Korshunov D.A., Sidorenko M.V., Yalov [7]) was used in the partial unloading of material by making one slot in the vicinity of the strain gauge.

The method of hole is based on the calculation of stress on local deformations caused by the hole drilling. Strain gauges are installed before drilling a hole and are usually positioned radially in relation to the latter. The required stresses are searched for according to the data of strain measurements in three directions [8-11]. The method is designed for plates, but can be used at the surface of an array with a sufficient depth of a hole (about 1.5 hole diameter). The method assumes the absence of local damage near the hole and the presence of elastic properties of the material, which for stone and concrete is carried out only under weak loading. The disadvantage of this method is that in order to determine stresses by the magnitude of the measured deformations, it is necessary to know the concrete strain modulus and the Poisson's ratio, which in turn depend on the magnitude of stresses. Therefore, in practice it is necessary to install the modulus of elasticity according to wellknown dependencies on the strength of concrete or directly in the structure as a result of testing samples of the same concrete or concrete extracted from a structure.

\subsection{Physical methods}

A number of physical methods for direct stress measurement is proposed. In this case, the need to determine the modulus of deformation goes away, the calculations are simplified. However, in these methods drawbacks can be found. The scope of an optical method [3] is limited to the study of models. The X-ray method $[12,13,14]$ is complex and dangerous and so far has a low accuracy. The method of magnetoelasticity $[15,16,17]$ for concrete can only be used indirectly. The method of nuclear magnetic resonance, as well as the measurement of energy of gamma rays [18], is still used for accurate physical experiments of homogeneous materials. It is known to use the method of acoustic emission $[19,20]$ in conjunction with local heating of concrete surface. The method is complex and not accurate enough. 


\subsection{Compensation methods}

In 1949, a method for direct measurement of stresses in concrete was proposed. [21]. The method consists in the formation of a "gap" in the concrete with the subsequent placement of a jack in it and the restoration of deformations. However, the accuracy of measuring stresses in concrete by this method is not high. The method was used in measuring the stresses of masonry pylons of St. Isaac's Cathedral in Leningrad (1963). The method makes it possible to determine only compressive stresses and only in one direction. With the internal tab of sensors there is a question of the ratio of sensor stiffness and the material.

The above-described methods for testing load-bearing structures of buildings and structures being used do not make it possible to identify the actual safety margins of structures. To improve the reliability of assessment of the carrying capacity of the tested structures when exposed to a load higher than operational, it is recommended to redetermine the stresses.

Analysis of the known methods has shown that with a slight modification of the local load-lifting method, it is possible to get rid of many drawbacks of this method and expand its scope. To do this, it is necessary to apply an outlet of sensors on the surface of reinforced concrete structure.

Make cuts around each sensor with the formation of a prismatic sample and remove the resulting sample with a sensor pasted on it. From the results of our tests it was obtained that, even with a sufficiently deep gash, the effect of an array on the sample is preserved. And only a complete extraction of a sample with the sensor gives guarantees about removing the influence of an array of the structure on the sample deformation. Removing the sample from the array provides other benefits. When testing a sample, we not only get a direct test of the magnitude of the stresses in a given fiber structure, but also a complete diagram of the concrete behavior in the extracted fiber structure. We can get the results of direct measurements of corrosion, material density, etc. It is possible to evaluate the history of operation of the fiber structure (using the memory effect) at the point under study and predict its further behavior.

Currently, the cutting of samples is carried out to determine the strength of concrete [79]. Therefore, it was proposed to develop a method for determining stresses in concrete of a reinforced concrete structure using the method of extracting a sample from an array.

\section{Test procedure}

It was found that the best way to obtain information about the state of a structure material is the method of extracting a sample from the operated structure with its subsequent testing. This is due to the fact that the modern construction of theories of strength is based on the testing of standard material samples.

The information obtained during the testing of a sample, makes it possible to build a diagram of concrete in the studied point in time. As far as it is known, the diagram integrally identifies all changes in the structure that have occurred in the material during its operation. Using models of the theory of degradation makes it possible to assess the overall picture of changes that have occurred in concrete and predict its behavior. The initial diagram of concrete behavior can also be obtained from the results of tests of concrete at the project age and according to the diagram laid down in the design standards.

The following sequence of actions is proposed.

1. A rectangular socket is laid out at the studied point of construction on which strain gauges are glued.

2. Cuts are made in accordance with the marked outlet.

3. The resulting prismatic elements are broken out. 
The difference in deformations of prismatic specimens before cutting and after its removal from the structure makes it possible to determine elastic $\left(\varepsilon_{e l}\right)$ fiber deformations of concrete [6]. The measured linear elastic deformations of strain gauges make it possible to calculate the main deformations $\varepsilon_{l, 2}$ and their directions using the formulas for a rectangular socket.

$$
\varepsilon_{1,2}=\frac{\varepsilon_{0}+\varepsilon_{90}}{2} \pm \frac{\sqrt{2}}{2} \cdot \sqrt{\left(\varepsilon_{0}-\varepsilon_{45}\right)^{2}+\left(\varepsilon_{45}-\varepsilon_{90}\right)^{2}}
$$

The resulting broken samples are sawn to form prisms of a size, for example, $25 \times 25 \times 100 \mathrm{~mm}$. The lateral cuts for each prism determine the structure of concrete and the volume content of the aggregate $\varphi$. Prisms are tested according to [7].

For testing prisms, it is proposed to use a special piston unit that allows testing of smallsized samples.

According to the test diagrams of small prisms and the difference of deformations of prismatic samples before breaking and after fiber stresses are defined and the corresponding stresses at the studied point of the structure. The modulus of elasticity of concrete is aligned on the basis of a bulk two-component model [8]:

$$
E_{M} / E_{P}=1 /\left(1+V_{Z} / V_{P}\left(E_{Z} / E_{M}-1\right)\right)
$$

where $E_{M}, V_{Z}, E_{Z}$ and $V_{P}, E_{P}$ is the modulus of elasticity of the matrix, the volume and the modulus of elasticity of the aggregate and entire prism, respectively.

The test results of small prisms showed that their strength does not exceed the strength of prisms of standard sizes. The diagrams are processed according to the theory of degradation with the identification of the highest level of stress reached at the point in question, the expected value of concrete creep, and the initial and modified modulus of concrete elasticity. [9]

\subsection{Refinement of the methods}

To refine the methodology, studies were carried out on concrete prisms with dimensions of 150x150x600 mm and blocks of 600x600x600 mm. Samples were made from prefabricated concrete of classes B7.5; B15; IN 20; and B30. The prism strength of concrete samples was within $12 \ldots 42 \mathrm{MPa}$. For the concrete manufacture was used: slag Portland cement Magnitogorsk cement plant M300 and M400, river sand 0-5 (Mk = 2.9) Agapoka quarry JSC "Magnitostroy", porphyritic crushed stone 10-20 granite pit JSC "Magnitostroy".

Table 1. Characteristics of the concrete mix.

\begin{tabular}{|c|c|c|c|}
\hline Composition & Class of concrete & $\begin{array}{c}\text { Volumetric weight of the mixture } \\
\mathrm{kg} / \mathrm{m} 3\end{array}$ & Mobility of the mixture, $\mathrm{cm}$ \\
\hline 1 & B7.5 & 2410 & 6.0 \\
\hline 2 & B15 & 2410 & 5.0 \\
\hline 3 & B20 & 2358 & 5.0 \\
\hline 4 & B30 & 2440 & 6.0 \\
\hline
\end{tabular}

The samples were tested under four loading methods (Fig.1). In table 2 the number of samples for each test is shown. 
Table 2. The number of samples tested.

\begin{tabular}{|l|c|c|c|c|c|c|}
\hline \multirow{2}{*}{ Name } & \multicolumn{7}{c|}{ Number of samples on the diagrams Fig.1.5 } \\
\cline { 2 - 7 } & \multicolumn{3}{c|}{ I } & II & III & IV \\
\hline The number of prisms without cutting out & \multicolumn{3}{c|}{8} & 8 & 8 & 8 \\
\hline The number of prisms by sawing & 8 & 8 & 8 & 4 & 4 & 4 \\
\cline { 2 - 7 } At levels of load & 0.5 & 0.6 & 0.8 & 0.6 & 0.6 & 0.6 \\
\hline The number of cubes & \multicolumn{7}{|c|}{12} & \multicolumn{2}{c|}{12} & 12 \\
\hline The samples age, days & \multicolumn{3}{|c|}{90} & \multicolumn{2}{c|}{90} & 365 \\
\hline
\end{tabular}

*At the age of 28 days. was tested 12 cubes and three cubes after long-term tests.

**Four prisms to be used to estimate shrinkage during all tests.

\subsection{Test procedure}

At each mode, three prisms of each composition were tested. The expected breaking load was determined by the results of the test cubes
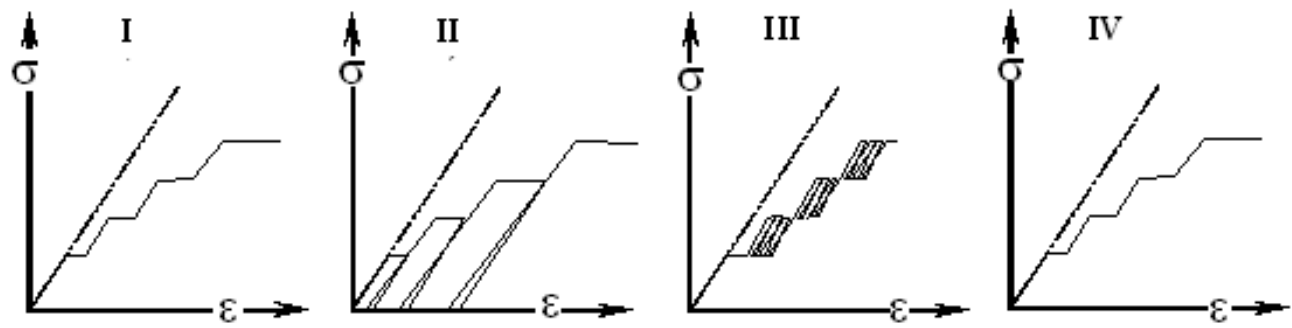

Fig. 1. Scheme of prisms loading.

Samples according to schemes I, II of Fig. 1 were tested according to [80] at the age of 90 days. The timing was determined by the need to remove the main part of the deformation shrinkage. Scheme III considered step-cyclic loading. With long-term loading scheme IV of fig. 1.5 was applied.

During the tests, the alignment of the samples was performed geometrically, and then along the physical axis at a loading level of 0.3 of the expected breaking load.

The shutter speed at the stage was 10 minutes prior to the load component of 0.7 of the intended destructive one. For the step a value of 0.1 from the expected breaking load was taken. At the stage the load was raised at a speed of $0.6 \mathrm{MPa} / \mathrm{s}$. After the level of 0.7 , the shutter speed was increased to 20 minutes. For conditional zero a load of $2 \%$ of the estimated breaking load was taken, where they also withstand 10 minutes.

Under cyclic loading, they stopped at the achievement of a complete cessation of the growth of inelastic deformations on the step for 60 minutes or after a triple loading.

Tests of samples according to schemes II, III and IV were carried out on a hydraulic stand with flat steel hydraulic jacks.

The stand makes it possible to simultaneously load from one to six samples with loads up to $2000 \mathrm{kN}$. The force accuracy was checked using a standard manometer and a $5000 \mathrm{kN}$ dynamometer introduced into one of the installations.

The criterion for termination of exposure at the stage for scheme IV Fig. 1.5 was the stabilization of deformations after a 15-day exposure of the sample under load served. Samples were tested in a climate chamber. The temperature maintained within $20 \pm 2{ }^{\circ} \mathrm{C}$ and relative humidity - $554 \%$ automatically.

Measurement of deformations was performed with hour-type indicators, Aistov strain gauges with a division value of $0.001 \mathrm{~mm}$ and strain gauges on a $50 \mathrm{~mm}$ base. 


\subsection{Cutting techniques for test samples}

In places where sensors were glued, the surface was carefully primed and dried. The sensors were set according to template and aligned on the risks. The sockets with sensors at angle of $45^{\circ}$ were used. Before the measurements, the sensors were dried for three days, then warmed up with a dryer for $20-30$ minutes at $\mathrm{t}=40-50^{\circ} \mathrm{C}$. The first measurements were made in a day.

To assess SSS methods two methods were applied:

- gluing a sensor, loading, cutting the prism with a sensor under load;

- loading of a sample, gluing a sensor, cutting the prism with a sensor under load.

A vertical strain gauge was glued to the concrete sample under load and after drying it was cut out. At the same time, a strain gauge pasted next to the sample, was loaded and removed. Filing was carried out in steps. At each step we measured the deformations. Two longitudinal cuts were made with a depth of $3 \mathrm{~mm}$; after that cross cuts by $3 \mathrm{~mm}$; cuts were adjusted to $5 \mathrm{~mm}$. Then, in $5 \mathrm{~mm}$ steps, the cuts were deepened to $30 \mathrm{~mm}$ and the resulting prismatic sample was broken out. After each stage, the exposure was 15 ... 20 minutes. Concrete heating temperature was controlled by a thermocouple. Heating of strain gauges when filing did not exceed $40^{\circ} \mathrm{C}$.

Using the laboratory samples with dimensions of 300x100x100 mm we studied the effect of cutting distance from the sensor, depth of cutting, length of sawing and recovery of deformations, heating temperature of concrete, power and speed of cutting disk rotation, thickness of the cutting disk. Longitudinal cutting was performed on $100 \mathrm{~mm}$ from the strain gauge. The subsequent ones were drawn nearer with a step of $10 \mathrm{~mm}$ (Fig. 1.7). 36 samples were tested (24 concrete of known composition, six mortar composition 1:3 and $1: 1)$.

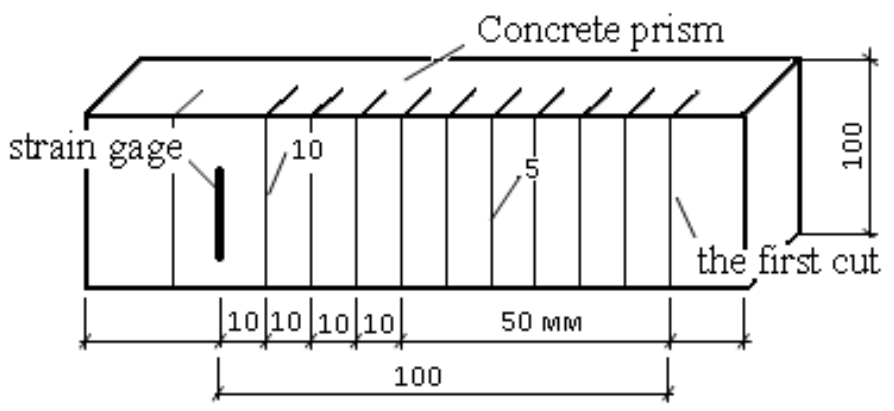

Fig. 2. Methods for longitudinal cuts execution.

On the basis of experiments conducted, the following recommendations were proposed for cutting out strain gages:

1. The distance from the axis of the strain gauge should be at least $10 \mathrm{~mm}$ in each direction due to the surface destruction area around the disk at the initial moment of cutting;

2. Saws with a depth of more than $10 \mathrm{~mm}$ should be made in several stages (no more than $5 \mathrm{~mm}$ for each cut) to prevent excessive heating of the cut sample. The time interval between cutting should ensure cooling of a sample to a temperature that differs by no more than $+10^{\circ} \mathrm{C}$ from the initial one;

3. To take into account changes in the ambient temperature during the cutting process, a mandatory labeling of the compensation sensor on this structure outside the cutting area is required; it is recommended to glue the strain gauge on the spot pre-sawed on all sides;

4. Restoration of deformations after cutting to a depth of $5 \mathrm{~mm}$ takes 20-25 minutes, deeper - up to several hours. Therefore, after cutting out the strain gauge from all sides to a depth of $45 \mathrm{~mm}$, it is recommended to break it out not earlier than in a day; recommended 
sample sizes for cutting at least $25 \times 25 \times 30$ for aggregate size up to $20 \mathrm{~mm}$ and $40 \times 40 \times 160$ $\mathrm{mm}$ for aggregate size up to $40 \mathrm{~mm}$;

From a large number of practiced means of hydro-measurement, a paraffin-vaseline mixture prepared from technical vaseline and paraffin by mixing in a heated state $(+70 \ldots$ $800^{\circ} \mathrm{C}$ ) was selected on the surface of building structures. In this case, the waterproofing composition covered both the strain gauges themselves and the connecting wires to the sections of 10-15 mm;

6. The most appropriate way to take into account the effect of temperature is to install temperature sensors, identical to the working ones, on the surface of the structure.

The results of experiments showed that the accuracy of stresses determination was $6 \pm 1.2 \%$.

\subsection{Test methods for full-scale structures}

To determine SSS on the existing structure, a rectangular socket of strain gauges with a base of $50 \mathrm{~mm}$ was glued onto a previously prepared surface. Glue BF-2 was used for sticking the strain gauges with their subsequent waterproofing. The process of gluing strain gauges was the same as in the laboratory. In addition, compensatory sensors were stuck on the construction sites sawn from all sides. Drying was carried out according to the method described above. Observations on the stability of the readings were carried out for one week. Then, samples of $160 \times 40 \times 40 \mathrm{~mm}$ were sawed out with sensors according to the above described method with their subsequent breaking out.

Samples were taken in reinforced concrete columns of a continuous section of industrial workshops and in supporting vertical panels of a nine-floor house at a height of $1.5 \mathrm{~m}$ from the floor level (Fig. 3). The columns were selected in the axes, where the most intensive crane operation of the given bay takes place.

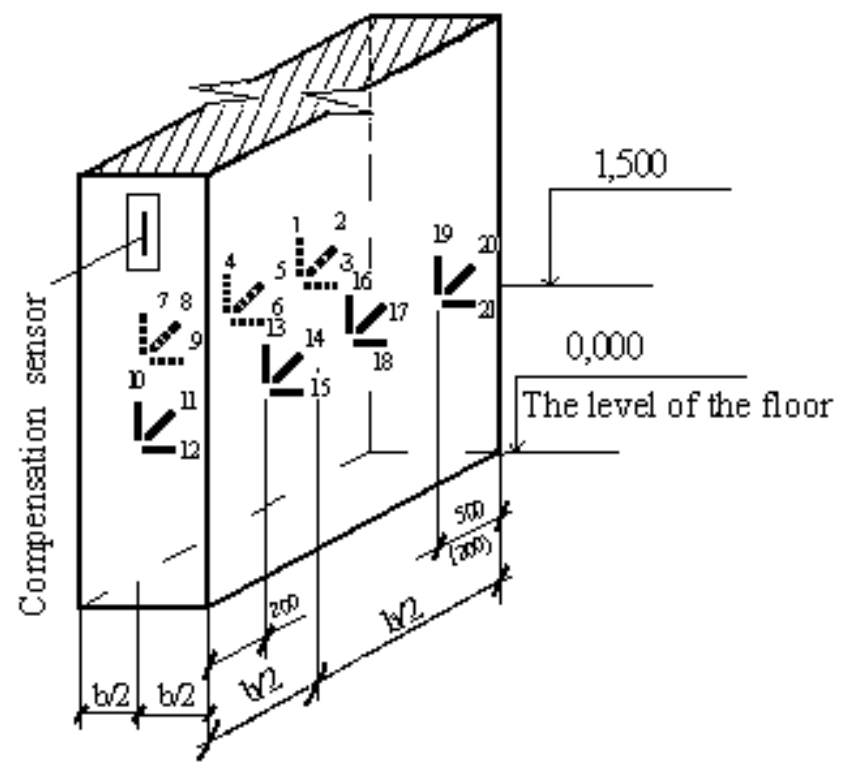

Fig. 3. The scheme of load cells gluing on the columns.

After cutting out the outlet of strain gauges, the obtained grooves were sealed with highstrength, fast-hardening compositions. Subsequent outlets were cut out in a day. The tests were carried out in a piston installation (Fig. 4.).

The modulus of elasticity was determined by testing broken samples of size 160x40x40 $\mathrm{mm}$ in a specially made piston unit on a scale of $100 \mathrm{kN}$ of a hydraulic press. Measurement 
of longitudinal deformations was carried out using hour-type indicators with a division value of $0.001 \mathrm{~mm}$ and using strain gauges. The installation design due to its rigidity and precision of manufacturing ensured the central loading of samples. Prisms were installed on gypsum at high-precision angles and pressed with a piston. The tests were carried out in one day after installation.

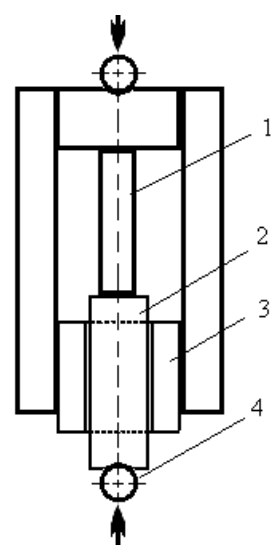

Fig. 4. Setup piston, where: 1 - tested sample; 2 - piston; 3 - frame installation; 4 - hinge.

According to the broken out samples the volume of coarse aggregate and mortar part were established by the ratio of the areas on the side surfaces. A comparison of this technique with the known actual composition of the experimental prisms showed that the measurement accuracy was $11 \%$ at a reliability level of 0.95 .

\subsection{The results of stresses determination in full-scale structures}

Practical development of the method took place in shaped-foundry shop of CJSC "Mechanical Repair Complex" PJSC "Magnitogorsk Iron and Steel Works" (iron and steel departments), as well as in residential nine-floor panel houses of series 121 in Magnitogorsk city. The steel casting department building is rectangular in plan with dimensions of 85.64-299 $\mathrm{m}$ and consists of four bays of one direction. It was commissioned in 1941. The building framework is made mainly in the form of monolithic reinforced concrete frames with a step of $6.5 \mathrm{~m}$ (within the melting section). All the bays are equipped with bridge cranes.

The iron foundry building is a complex form in plan with overall dimensions of $162.5 \mathrm{x}$ $91.08 \mathrm{~m}$ and consists of five longitudinal and two transverse bays. It was commissioned in 1933. The building frame is made mainly in the form of monolithic reinforced concrete frames with a step of $6.5 \mathrm{~m}$; all the bays, with the exception of D-E, are equipped with bridge cranes with a lifting capacity from 5 to 40 tons.

The effective stresses were determined under the action of a constant load (the cranes were removed). We determined the proportion of stress added when bridge cranes approached to the columns. To do this, we measured the deviations of the strain gauges during operation of one crane in the bay and several cranes with different weights and modes of operation during the work shift.

Since the samples taken from the constructions are smaller than the standard, the obtained results were compared. When sawing out of standard samples in the laboratory, the variation of the strength and deformative characteristics of small samples and standard prisms did not exceed 14\%. When sawing out in a panel of a nine-floor house, a prism of $120 \times 120 \times 480 \mathrm{~mm}$ was made at the area of future opening and was tested in a laboratory. 
The strength of the prism was less than the average strength obtained from the results of tests of samples of sizes $40 \times 40 \times 160 \mathrm{~mm}$ by $8 \%$. The slight difference in the results of tests of standard prisms and small-sized samples can be explained by weakening of concrete prisms that appear when sawing and breaking out, as well as eccentricities arising from small samples testing.

The samples test results taken from the shop columns and the nine-floor panel residential building are shown in the figures, where the following abbreviations are taken:

DCS-K21-A-1 - department of casting of steel, column №21 on axis "A", sensor No1;

DCIC-K23-A-3 - department of cast iron casting, column №23 on axis "A", sensor No 3.

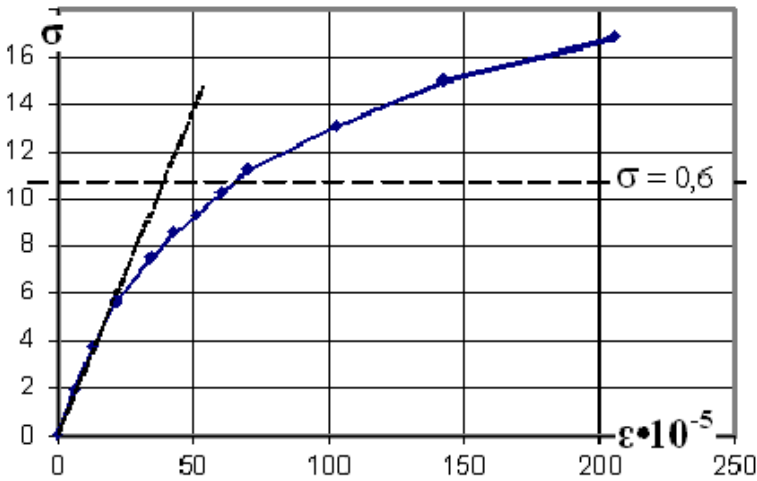

Fig. 5. The dependence of relative deformations from stress sensors 1 and 3, a nine-floor house.
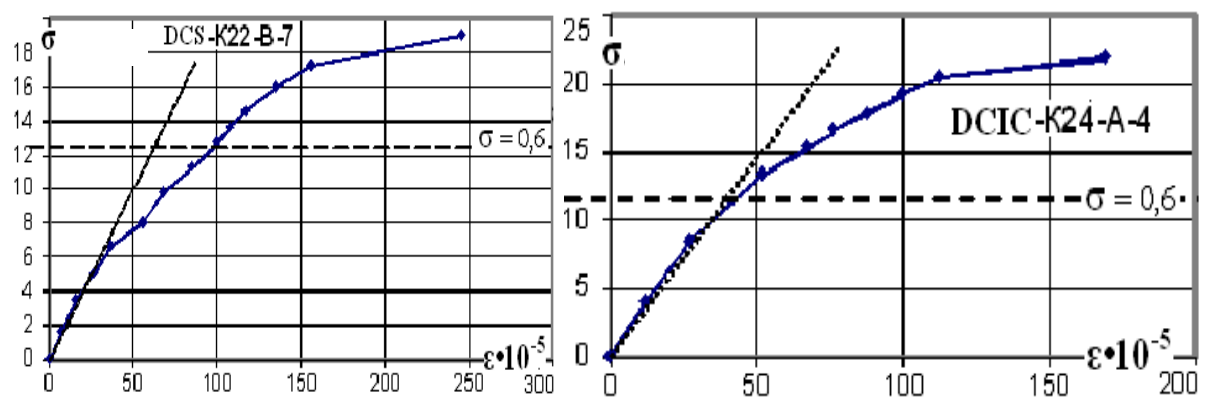

Fig. 6. The dependence of relative deformation from stress.

According to the test results of samples and the available data obtained in the process of cutting, the effective stresses in the structures are determined. The main results of effective stresses determination in the structures are summarized in Table 3.

Table 3. Working table of cuts DCS-K23.

\begin{tabular}{|c|c|c|c|c|c|c|c|c|c|}
\hline Note & $\begin{array}{c}1 \text { Sensor } \\
\text { Vertic. }\end{array}$ & $\begin{array}{l}2 \text { Sensor } \\
\text { Vertic. }\end{array}$ & $\begin{array}{l}3 \text { Senso } \\
\text { Vertic. }\end{array}$ & $\begin{array}{l}4 \text { Sensor } \\
\text { Vertic. }\end{array}$ & $\begin{array}{c}5 \text { Sensor } \\
\text { Vertic. }\end{array}$ & $\begin{array}{c}6 \text { Sensor } \\
\text { Horiz. }\end{array}$ & $\begin{array}{l}7 \text { Sensor } \\
\text { Under } 45^{0}\end{array}$ & Date & $\begin{array}{l}\mathrm{T}, \\
{ }^{0} \mathrm{C}\end{array}$ \\
\hline 23.08. Sticker sensors & 1080 & - - & 1000 & 960 & 1040 & 1010 & 990 & 28.08 & 15 \\
\hline 24.08. water & & - & 85 & 880 & 945 & 1170 & 930 & 29.08 & 17 \\
\hline 28.08. Sticker sensors & 105 & 970 & 840 & 920 & 1010 & 1010 & 940 & 30.08 & 19.8 \\
\hline 29.08 waterproofing & 1090 & 1000 & 950 & 940 & 1010 & 990 & 970 & 31.08 & 17 \\
\hline Before performing the cuts & 1180 & 1100 & 920 & 1040 & 1110 & 1110 & 1060 & 3.09 & 15 \\
\hline Thr & & & 89 & & 1055 & 1030 & 100 & 4.09 & 18 \\
\hline Befor to extract & 1510 & 1050 & 910 & 950 & 1100 & 1040 & 1010 & 5.09 & 18 \\
\hline After extraction & 1550 & 1270 & 1010 & 1260 & 1600 & - & 1035 & 5.09 & 18 \\
\hline After one hour & 1510 & 1230 & 900 & 920 & 1410 & - & 1130 & 10.09 & 20 \\
\hline
\end{tabular}

Note: the second sensor is pasted to the sawn surface made in advance. 
Table 4. The nine-floor house series 121.

\begin{tabular}{|c|c|c|c|c|c|c|}
\hline $\begin{array}{c}\text { № } \\
\text { sensor }\end{array}$ & $\begin{array}{c}\text { Module } \\
\mathrm{E}, \mathrm{MPa}\end{array}$ & $\begin{array}{c}\varepsilon_{\mathrm{el}}, \\
10^{-5}\end{array}$ & $\begin{array}{c}\sigma_{\text {exp. }} \\
\mathrm{MPa}\end{array}$ & $\begin{array}{c}\mathrm{R}_{\mathrm{b}}, \\
\mathrm{MPa}\end{array}$ & $\begin{array}{c}\text { Theoretical voltage from } \\
\text { full load, } \sigma_{\text {th. }}, \mathrm{MPa}\end{array}$ & $\sigma_{\text {exp }}^{\max }, \mathrm{MPa}$ \\
\hline 1 & 29800 & 4 & 1.19 & 18.7 & 1.32 & 6 \\
2 & 32100 & 5 & 1.61 & 18.2 & 1.32 & - \\
3 & 31000 & - & - & 18.4 & - & 5.7 \\
4 & 29500 & 1 & 0.29 & 21.7 & - & 5 \\
5 & 30100 & 4.5 & 1.35 & 18.2 & 1.32 & 4 \\
7 & 27500 & - & - & 19.2 & 1.32 & 5 \\
\hline
\end{tabular}

Table 5. Samples DCS-K22-B.

\begin{tabular}{|c|c|c|c|c|c|c|c|}
\hline $\begin{array}{c}\text { № } \\
\text { sensor }\end{array}$ & $\begin{array}{c}\text { Module } \\
\text { E, MPa }\end{array}$ & $\begin{array}{c}\varepsilon_{\text {el }}, \\
10^{-5}\end{array}$ & $\begin{array}{c}\sigma_{\text {exp., }} \\
\text { MPa }\end{array}$ & $\begin{array}{c}\mathrm{R}_{\mathrm{b}}, \\
\text { MPa }\end{array}$ & $\begin{array}{c}\sigma_{\text {th }} \text { constant } \\
\text { load, MPa }\end{array}$ & $\begin{array}{c}\sigma_{\text {th }} \text { full } \\
\text { load, MPa }\end{array}$ & $\sigma_{\text {exp }}^{\max }, \mathrm{MPa}$ \\
\hline 1 & 25600 & 18.0 & 4.6 & 35.3 & 3.07 & 11.43 & 5.0 \\
4 & 25100 & 6.5 & 1.6 & - & 2.53 & 9.58 & - \\
7 & 22000 & 3.4 & 0.7 & 21.9 & 1.56 & 6.27 & 7.5 \\
13 & 23000 & 3.4 & 0.8 & - & 1.59 & 6.40 & - \\
16 & 24700 & 6.8 & 1.7 & 20.6 & 2.58 & 9.78 & 10.5 \\
17 & 24000 & 0.3 & 0.1 & - & - & - & - \\
\hline
\end{tabular}

Table 6. Samples DCS-K23-A.

\begin{tabular}{|c|c|c|c|c|c|c|c|}
\hline $\begin{array}{c}\text { № } \\
\text { sensor }\end{array}$ & $\begin{array}{c}\text { Module } \\
\text { E, MPa }\end{array}$ & $\begin{array}{c}\varepsilon_{\mathrm{el}}, \\
10^{-5}\end{array}$ & $\begin{array}{c}\sigma_{\text {exp., }} \\
\mathrm{MPa}\end{array}$ & $\begin{array}{c}\mathrm{Rb} \\
\mathrm{MPa}\end{array}$ & $\begin{array}{c}\sigma_{\text {th }} \text { constant } \\
\text { load, MPa }\end{array}$ & $\begin{array}{c}\sigma_{\text {th full load, }} \\
\mathrm{MPa}\end{array}$ & $\sigma_{\text {exp }}^{\max }, \mathrm{MPa}$ \\
\hline 1 & 29700 & 2.3 & 0.7 & 11.5 & 0.94 & 3.08 & - \\
4 & 34300 & 12.4 & 4.3 & 10.1 & 1.12 & 3.92 & 4.0 \\
7 & 25700 & 15.0 & 3.9 & 13.9 & 1.32 & 4.82 & 5.8 \\
10 & 29000 & 3.4 & 1.0 & 12.5 & 1.43 & 5.30 & - \\
16 & 28400 & 9.0 & 2.6 & 9.8 & 1.08 & 3.74 & 4.0 \\
18 & 29100 & 0.3 & 0.1 & 11.0 & - & - & - \\
\hline
\end{tabular}

Table 7. Samples DCS-K20-A.

\begin{tabular}{|c|c|c|c|c|c|c|c|}
\hline $\begin{array}{c}\text { № } \\
\text { sensor }\end{array}$ & $\begin{array}{c}\text { Module } \\
\text { E, MPa }\end{array}$ & $\begin{array}{c}\varepsilon_{\mathrm{el}}, \\
10^{-5}\end{array}$ & $\begin{array}{c}\sigma_{\text {exp., }} \\
\mathrm{MPa}\end{array}$ & $\begin{array}{c}\mathrm{R}_{\mathrm{b},} \\
\mathrm{MPa}\end{array}$ & $\begin{array}{c}\sigma_{\text {th }} \text { constant } \\
\text { load, MPa }\end{array}$ & $\begin{array}{c}\sigma_{\text {th full load, }} \\
\text { MPa }\end{array}$ & $\sigma_{\text {exp }}^{\max }, \mathrm{MPa}$ \\
\hline 1 & 23700 & 18.0 & 1,63 & 21.2 & 0.92 & 2.99 & 5.0 \\
\hline 7 & 26800 & 10.5 & 2,8 & 18.4 & 1.33 & 4.88 & 10.0 \\
\hline 10 & 25000 & 6.5 & 4,19 & 19.2 & 1.43 & 5.30 & - \\
\hline 16 & 33200 & 10.1 & 3,3 & 17.3 & 1.01 & 3.38 & - \\
\hline 17 & 28900 & - & - & 18.1 & - & - & - \\
\hline
\end{tabular}

Table 8. Samples DCS-K22-A.

\begin{tabular}{|c|c|c|c|c|c|c|c|}
\hline $\begin{array}{c}\text { № } \\
\text { sensor }\end{array}$ & $\begin{array}{c}\text { Module } \\
\mathrm{E}, \mathrm{MPa}\end{array}$ & $\begin{array}{c}\varepsilon_{\text {el }}, \\
10^{-5}\end{array}$ & $\begin{array}{c}\sigma_{\text {exp., }} \\
\mathrm{MPa}\end{array}$ & $\begin{array}{c}\mathrm{R} \mathrm{b}, \\
\mathrm{MPa}\end{array}$ & $\begin{array}{c}\sigma_{\text {th }} \text { constant } \\
\text { load, } \mathrm{MPa}\end{array}$ & $\begin{array}{c}\sigma_{\text {th full load, }} \\
\mathrm{MPa}\end{array}$ & $\sigma_{\text {exp }}^{\max }, \mathrm{MPa}$ \\
\hline 4 & 29300 & 9.8 & 1.76 & 16.6 & 1.0 & 3.35 & 4.6 \\
\hline 5 & 17200 & 2.0 & 0.34 & 21.7 & - & - & 1.0 \\
\hline 10 & 21900 & 12.0 & 2.80 & 22.3 & 1.43 & 5.30 & 6.2 \\
\hline 11 & 23600 & 1.4 & 0.31 & 31.0 & - & - & 0.9 \\
\hline 16 & 18700 & 2.4 & 0.45 & 28.2 & 0.9 & 2.93 & 3.3 \\
\hline
\end{tabular}

Table 9. Samples DCS-K21-A

\begin{tabular}{|c|c|c|c|c|c|c|c|}
\hline $\begin{array}{c}\text { № } \\
\text { sensor }\end{array}$ & $\begin{array}{l}\text { Module } \\
\text { E, MPa }\end{array}$ & $\begin{array}{l}\varepsilon_{\mathrm{el}}, \\
10^{-5}\end{array}$ & $\begin{array}{l}\sigma_{\text {exp., }} \\
\text { MPa }\end{array}$ & $\begin{array}{l}\mathrm{R}_{\mathrm{b}} \\
\mathrm{MPa}\end{array}$ & $\begin{array}{c}\sigma_{\text {th }} \text { constant } \\
\text { load, MPa }\end{array}$ & $\begin{array}{c}\sigma_{\text {th }} \text { full load, } \\
\mathrm{MPa}\end{array}$ & $\sigma_{\exp }^{\max }, \mathrm{MPa}$ \\
\hline 1 & 24100 & 3.5 & 0.84 & 22.6 & 0.88 & 2.84 & 5.0 \\
\hline 2 & 22800 & 1.7 & 0.38 & 24.1 & - & - & 2.2 \\
\hline 12 & 20600 & 2.8 & 0.57 & 17.7 & - & - & 4.0 \\
\hline 10 & 25600 & 3.9 & 0.99 & 19.6 & 1.43 & 5.30 & 5.9 \\
\hline
\end{tabular}


Table 10. Samples DCIC -K23-A.

\begin{tabular}{|c|c|c|c|c|c|c|}
\hline $\begin{array}{c}\text { № } \\
\text { sensor }\end{array}$ & $\begin{array}{c}\text { Module } \\
\mathrm{E}, \mathrm{MPa}\end{array}$ & $\begin{array}{c}\varepsilon_{\mathrm{el}}, \\
10^{-5}\end{array}$ & $\begin{array}{c}\sigma_{\text {exp., }} \\
\mathrm{MPa}\end{array}$ & $\begin{array}{c}\mathrm{Rb}, \\
\mathrm{MPa}\end{array}$ & $\begin{array}{c}\sigma_{\text {th constant }} \\
\text { load,MPa }\end{array}$ & $\sigma_{\text {exp }}^{\max }, \mathrm{MPa}$ \\
\hline 10 & 30000 & 4.8 & 1.44 & 18.5 & - & 4.5 \\
\hline 19 & 35800 & 2.5 & 0.89 & 20.0 & - & 4.0 \\
\hline
\end{tabular}

Table 11. Samples DCIC -K24-A.

\begin{tabular}{|c|c|c|c|c|c|c|}
\hline $\begin{array}{l}\text { № } \\
\text { sensor }\end{array}$ & $\begin{array}{l}\text { Module } \\
\text { E, MPa }\end{array}$ & $\begin{array}{l}\varepsilon_{\mathrm{el}}, \\
10^{-5}\end{array}$ & $\begin{array}{l}\sigma_{\text {exp. }}, \\
\mathrm{MPa}\end{array}$ & $\begin{array}{l}\mathrm{Rb}, \\
\mathrm{MPa}\end{array}$ & $\begin{array}{c}\sigma_{\text {th }} \text { constant } \\
\text { load, } \mathrm{MPa}\end{array}$ & $\sigma_{\exp }^{\max }, \mathrm{MPa}$ \\
\hline 4 & 33800 & 6.4 & 2.2 & 22.2 & - & 9.0 \\
\hline 7 & 36200 & 4.6 & 1.7 & 16.0 & - & 5.5 \\
\hline 10 & 27600 & 6.1 & 1.7 & 19.6 & - & 6.0 \\
\hline
\end{tabular}

From the analysis of obtained theoretical and actual diagrams, the following conclusions were made:

1. On the experimental diagrams, it is possible to determine the maximum stresses acting during the operation (manifestation of the memory effect). These are the points of diagrams deviation from the straight line characterizing the initial modulus of elasticity of concrete (the straight dashed line in the graphs). For example, in a nine-floor building, the deviation from the modulus of elasticity occurred at stresses of 4-6 MPa, with effective stresses of 1.3-1.6 MPa; in column 22, row "B" of steel department, this point corresponded to 5-10.5 MPa, the effective stresses from the most loaded face from the constant load were 4.6 $\mathrm{MPa}$, the maximum calculated stresses were $12.8 \mathrm{MPa}$. From this we can conclude that, in general, concrete of the studied structures worked in the field of low stresses. Therefore, plastic deformations were not selected, and the experimental diagrams were well described by theoretical curves. The effective stresses determined using the proposed method are 0.25 - 0.42 of the breaking load without taking into account crane effects. Crane loads in steel and iron foundry compartments additionally introduced stresses equal to 0.11 up to $0.25 \%$ of the stresses under the action of a constant load.

2. As it can be seen from table. 5.1, the values of resulting stresses for a nine-floor building differ from the theoretical ones by $2-20 \%$. The stresses defined in the columns of the workshops exceed theoretical values (Table 5.2 - 5.5). The actual eccentricity of load in the columns is greater than the theoretical. For example, for column 22 in row "B" of the department, the theoretical value of $\mathrm{e} / \mathrm{h}$ in the longitudinal direction was 0.06 . After cutting the samples, the ratio $\mathrm{e} / \mathrm{h}=0.128$ in the longitudinal direction, but it also revealed the presence of eccentricity in the transverse direction and $\mathrm{e} / \mathrm{b}=0.07$. The value of current eccentricity exceeded the theoretical value by two times in the longitudinal direction, and the value of eccentricity in the transverse direction was equal to the theoretical value in the longitudinal direction. As the consequence of presence of eccentricities in both directions, the cross section of the columns is loaded unevenly.

3. The strength distribution of cut samples for a nine-floor building was $13.8 \%$, for workshops $15.9 \%$ of the average value. Large distribution (up to $36 \%$ ) was in columns SLO-K22-B and SLO-K22-A. This is due to significant defects in the structure of concrete in the cut samples (pores from 1 to $5 \mathrm{~mm}$ in size, inclusions of aggregate with a crosssection of more than $30 \mathrm{~mm}$ ), which were formed during monolithic construction.

In all the elements under study, the stresses in horizontal sensors were tensile, 0.1-0.3 MPa.

\section{Conclusion}

The developed method made it possible to determine the effective stresses in the existing reinforced concrete structures. It was found that the actual magnitudes of operating stresses 
and eccentricities of the applied load in the structures under study are greater than the theoretical ones. The results of experiments showed that the structures under study operate mainly at a level of stresses not exceeding the value of 0.5 of prism strength. The resulting model of concrete with sufficient accuracy for practical purposes (discrepancy $1 \mathrm{j} 15 \%$ ) describes the behavior of concrete.

The application of proposed method for constructing a concrete model and the model itself, together with the developed method for determining stresses in concrete, provides information on changes in the deformative and strength characteristics of concrete during operation and more adequately assess the state of structures during inspections and residual life. We also determined the highest level of stresses in force in the structures during their operation.

\section{References}

1. G.J. Pochtovik, A.B. Zlochevsky, A.I. Yakovlev, Methods and means of testing building constructions (Higher school, Moscow, 1973)

2. V.B. Jakubowski, N.N. Ermolaev, D.V. Acridine, Testing of concrete structures and constructions (Higher school, Moscow, 1965)

3. I.P. Sukharev, Experimental methods of research of deformations and strength (Mashinostroenie, Moscow, 1987)

4. I.A. Krylov, K.A. Glukhov, Test structures (Leningrad, 1970)

5. P.A. Pavlov, Dis. Cand.tech. Sciences (Moscow, 1955)

6. A.B. Zlochevsky, Experimental methods in structural mechanics (Stroiizdat, Moscow, 1983)

7. D.A. Korshunov, M.V. Sidorenko, G.N. Yalov, Concrete and reinforced concrete 3, 15 (1993)

8. D.G. Kurnosov, M.V. Yakubovich, Factory laboratory XII, 11-12 (1946)

9. O.N. Mikhailov, Factory laboratory XIX, 2 (1953)

10. V.P. Maltsev, Works of MIIT (1950)

11. K.P. Milbredt, PSESA IX, 1 (1951)

12. K. Fink, Measuring stresses and strains (Mashgiz, Moscow, 1961)

13. V.I. Feodosiev, Resistance of materials (Nauka, Moscow, 1964)

14. L.I. Mirkin, Handbook of x-ray diffraction analysis of polycrystals (Moscow, 1961)

15. G.I. Shevchenko, Magnetic anisotropic sensors (Energiya, Moscow, 1967)

16. A.A. Pashkevich, Materials for the Symposium "Experimental investigations of engineering structures (Leningrad, 1965)

17. K.K. Kvartskhava, Concrete and reinforced concrete 8, 26 - 27 (1981)

18. D. Benedek Physics of the solid state 8, 101-110 (1972)

19. V.V. Gureev, Dissertation of the candidate of technical Sciences (Moscow,1989)

20. A.M. Sagaidak, Dissertation of the candidate. of technical Sciences (Moscow, 1992)

21. S.V. Bugaenko, A.I. Chubukov, S.M. Skorobogatov, A.V. Kershpel, Construction and education 4, 84-85 (2000)

22. A.A. Varlamov, Concrete and reinforced concrete 3, 27-30 (2012)

23. A.A. Varlamov, Izvestiya KGASU 29,19-26 (2014) 